Supporting information

\title{
Electrochemical Biosensor Based on Integrated Assembly of Dehydrogenase Enzymes and Gold Nanoparticles
}

\author{
Bikash Kumar Jena and C. Retna Raj* \\ Department of Chemistry, Indian Institute of Technology, Kharagpur, \\ 721 302, India. E-mail: crraj@chem.iitkgp.ernet.in \\ Fax: +91-3222-282252; Tel: +91-3222-283348
}

\section{Figure 1S}

(A) Absorption spectra of nano-sized AuNPs on MPTS monomer functionalized glass slide before (a) and after hydroxylamine seeding (b); (c) spectrum obtained for the glass slide before the self-assembling of AuNPs.

(B) UV-visible diffuse reflection spectra of AuNPs on MPTS sol-gel network modified gold-coated glass slide. Other conditions are same as in Figure 1S(A).

\section{Figure 2S}

FTIR spectra obtained for MPTS sol-gel network before (A, B) and after (C) selfassembling of Au nanoparticles. Selected regions are given for clarity reason.

\section{Figure 3S}

XRD pattern obtained for hydroxylamine enlarged AuNPs on MPTS functionalized glass slide.

\section{Figure 4S}

(A) Cyclic voltammograms for $\mathrm{Fe}(\mathrm{CN})_{6}{ }^{4-/ 3-}$ redox couple in $0.1 \mathrm{M} \mathrm{KCl}$ on (a) polycrystalline $\mathrm{Au}$, (b) MPTS sol modified Au, (c) nAu and (d) nAuS electrodes. Scan rate $100 \mathrm{mV} / \mathrm{s}$. (B) Corresponding impedance plots; The $R_{c t}$ values calculated from the plot are: polycrystalline Au: 1.246 × $10^{3}$; MPTS-Au: 17 x 10 $0^{3}$; nAu: 1.5 x $10^{3}$; nAuS: $1.05 \times 10^{3} \Omega$. 


\section{Figure 5S}

(A) Hydroxylamine seeding time dependent response of $\mathrm{nAu}$ electrode towards the oxidation of NADH (0.5 mM). The electrode was soaked into the seeding solution for (a) 0, (b) 1, (c) 5, (d) 10 and (e) 20 minute. (B) Plot of peak potential and peak current against seeding time.

\section{Figure 6S}

(A) Cyclic voltammograms for the oxidation of NADH $(0.5 \mathrm{mM})$ on $\mathrm{nAuS}$ electrode at different scan rate in 0.1 M PBS. Scan rate: (a) 10, (b) 20, (c) 30, (d) 50 and (e) $70 \mathrm{mV} / \mathrm{s}$. (B) Plot of peak current against square root of scan rate.

\section{Figure 7S}

Plot of current vs. time for the oxidation of NADH $(0.1 \mathrm{mM})$ in $0.1 \mathrm{M}$ PBS demonstrating the (A) operational and (B) long time storage stability of the nAuS electrode. The electrode was used for the detection of NADH in 0.1 M PBS on every day and kept in PBS solution after measurement. 

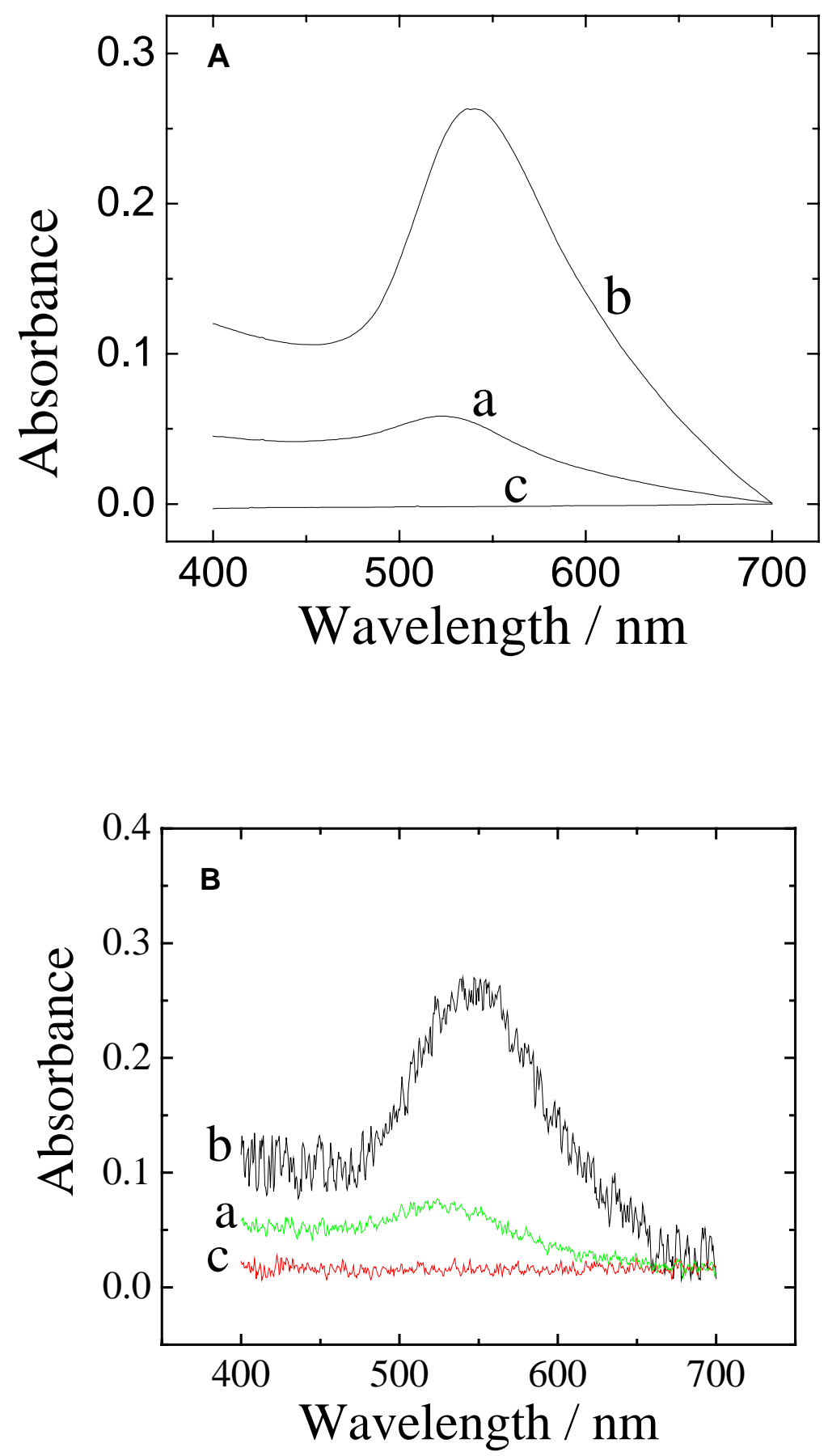

Figure 1S

Raj, C.R. 

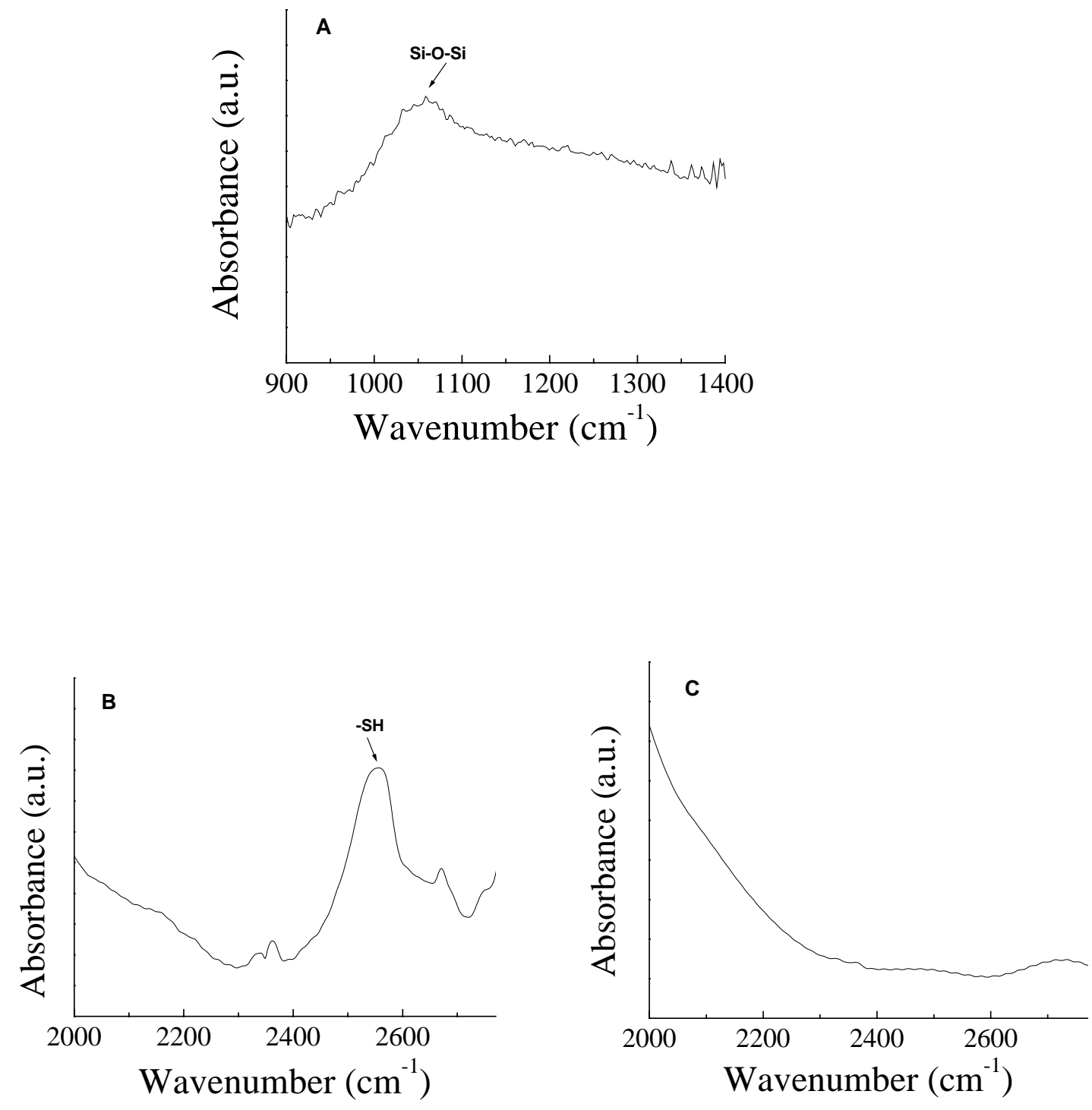

Figure 2S

Raj, C.R. 


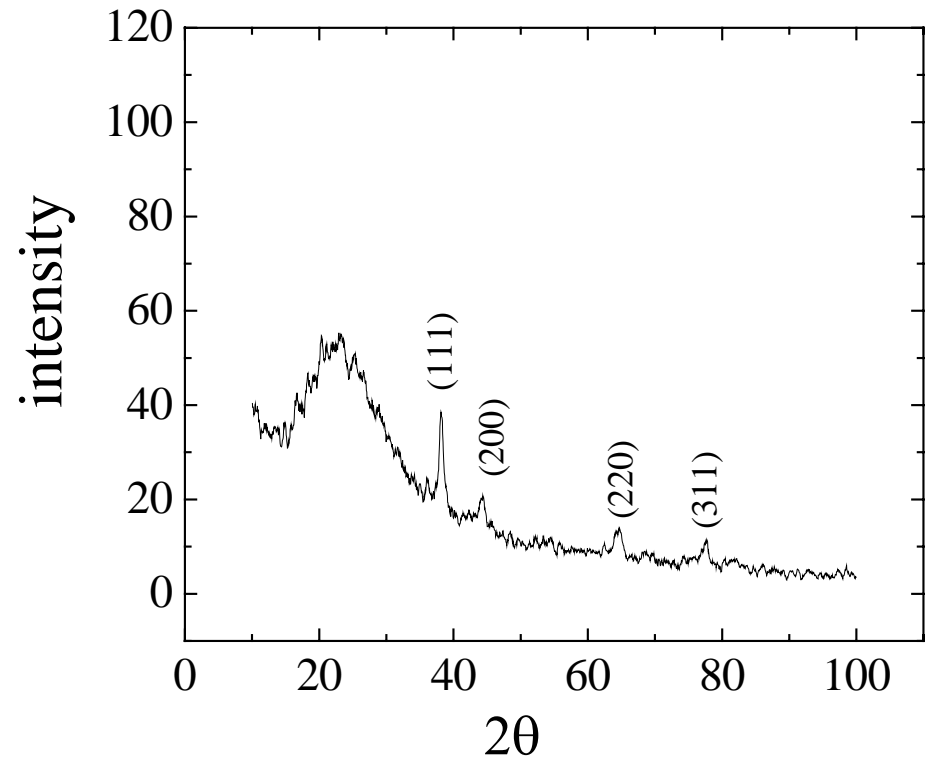

Figure 3S

Raj, C.R. 

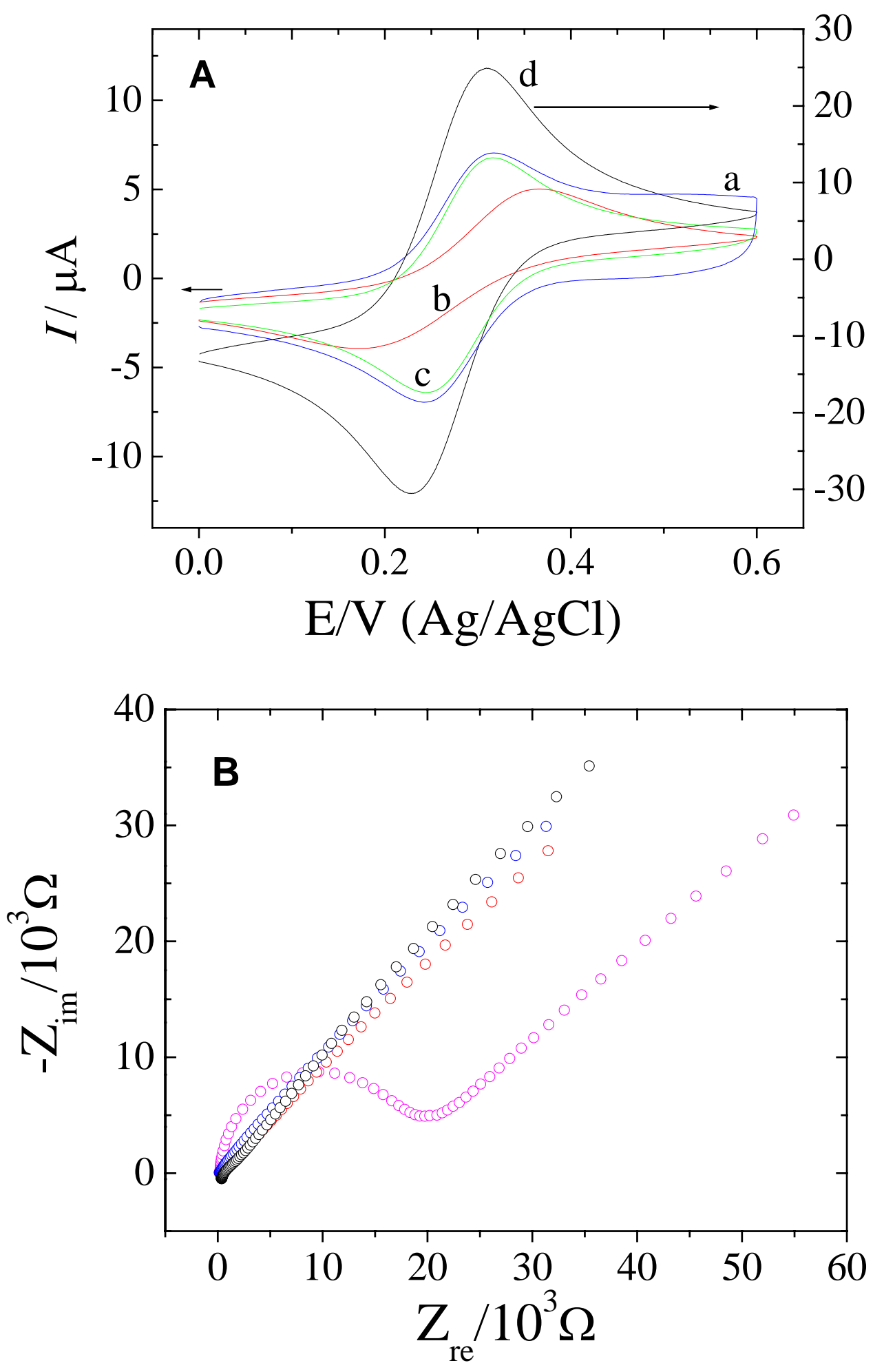

Figure 4S

Raj, C.R. 

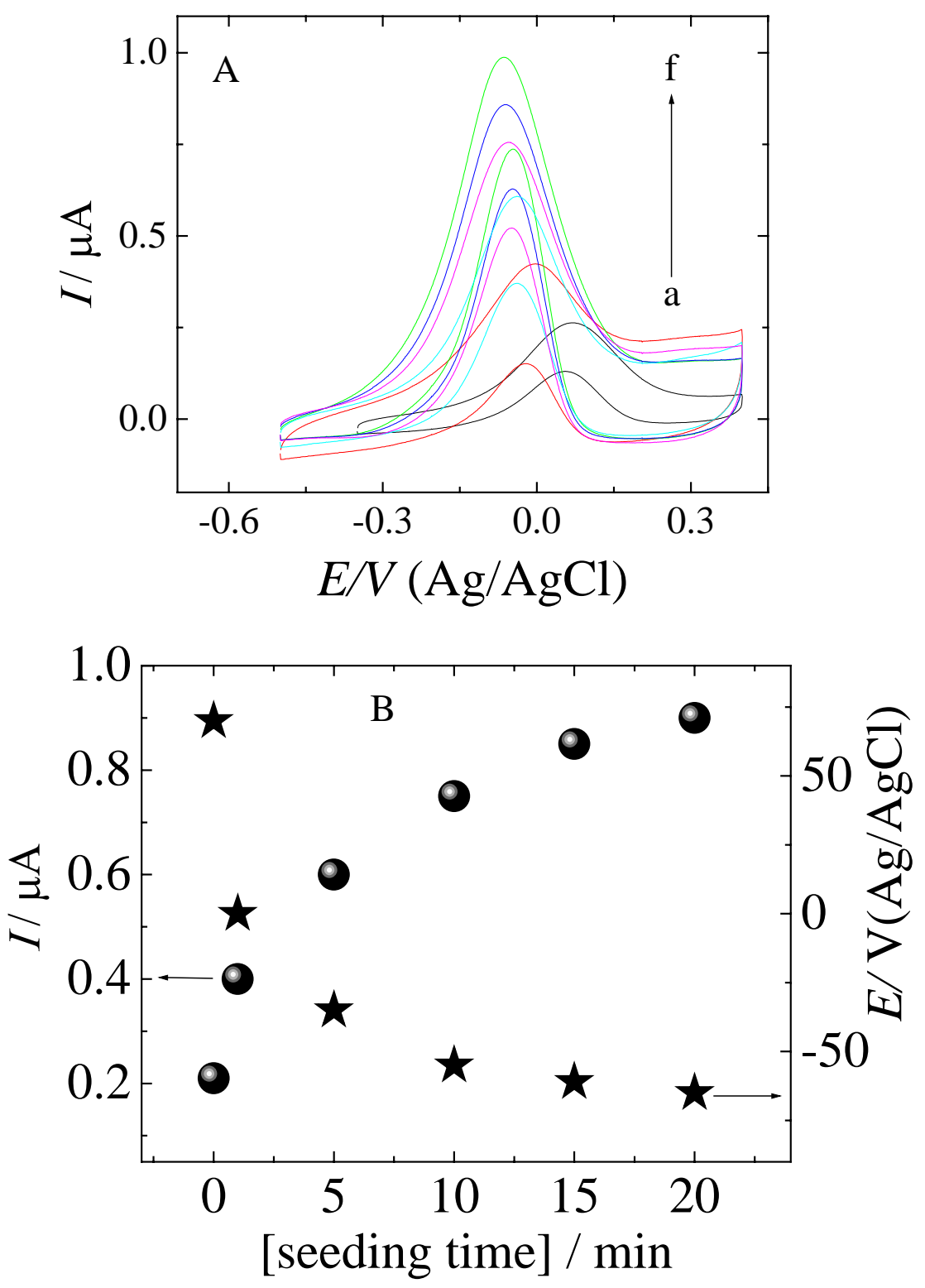

Figure 5S

Raj, C.R. 

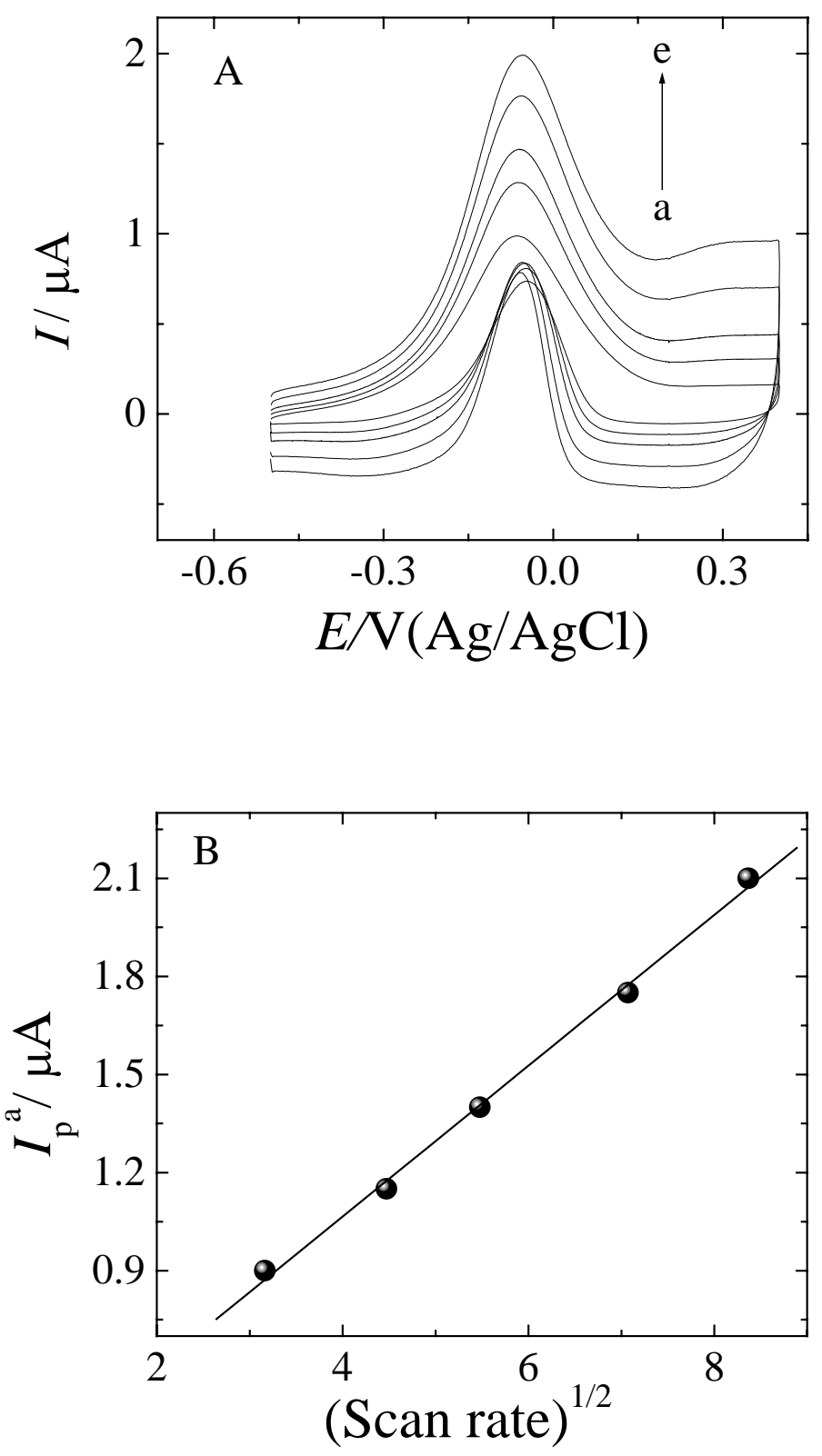

Figure 6S

Raj, C.R. 

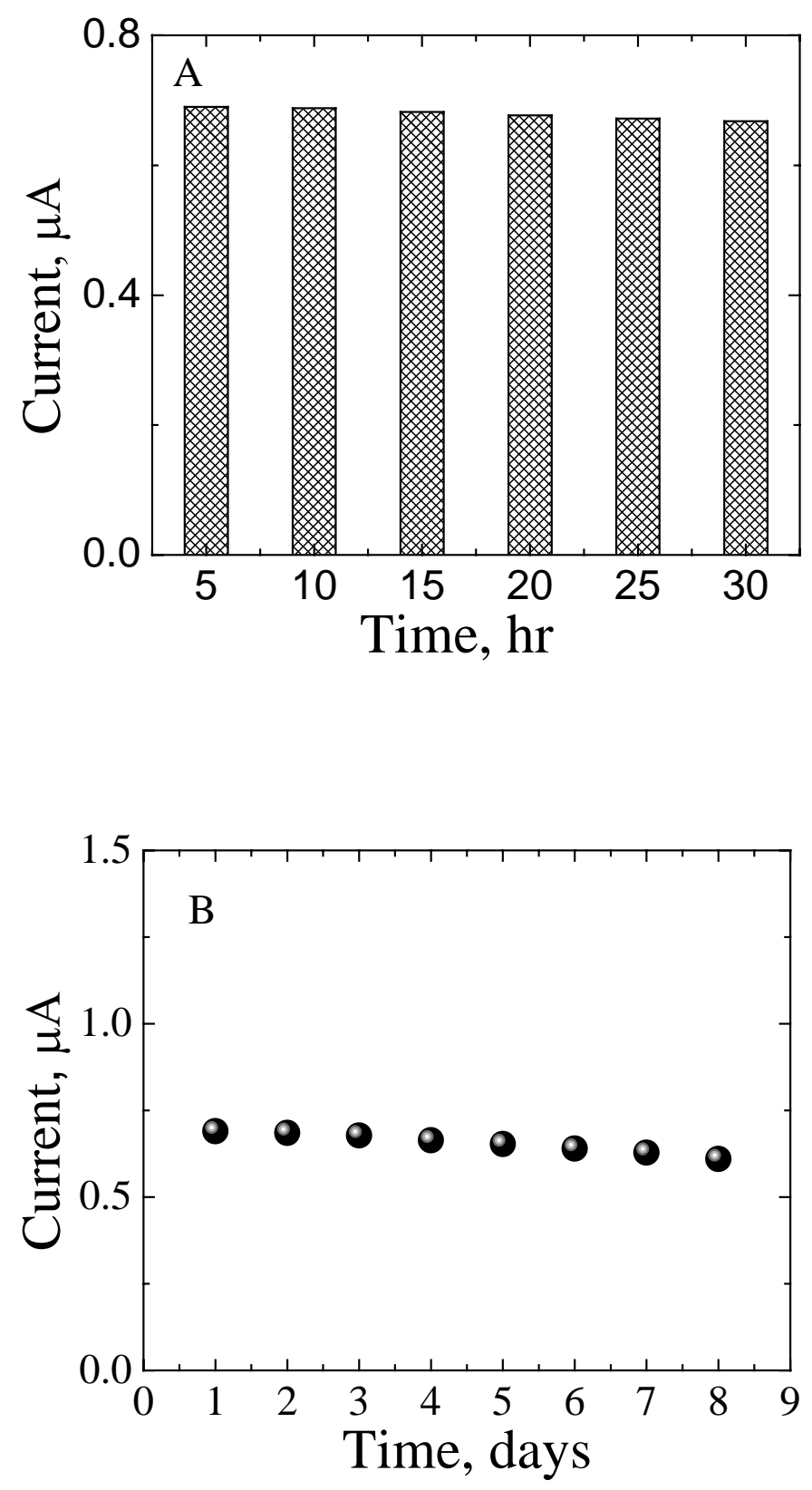

Figure 7S 